\title{
Researching on Buckling Performance of Corrugated Steel Web
}

\author{
Zhu Xudong, Li Ming, Li Yong \\ School of Civil Engineering, University of South China, Hengyang City, China \\ Email address: \\ 765494626@qq.com (Zhu Xudong), 1121446131@qq.com (Li Ming), 1091797239@qq.com (Li Yong)
}

To cite this article:

Zhu Xudong, Li Ming, Li Yong. Researching on Buckling Performance of Corrugated Steel Web. American Journal of Civil Engineering. Vol. 6, No. 1, 2018, pp. 5-10. doi: 10.11648/j.ajce.20180601.12

Received: October 7, 2017; Accepted: October 18, 2017; Published: December 6, 2017

\begin{abstract}
The paper mainly studies buckling performance about corrugated steel web composite box girder of corrugated steel web under the action of a shear. Compare the two results of the corrugated steel web that calculating critical buckling stress through Abaqus finite element software calculating and theory formula. Obtain buckling strength of the model by giving the model initial defects under the elastic condition merely. In this paper, research trend of the buckling strength of corrugated steel web plate through changing the thickness of corrugated steel web, Angle, length of straight and wave height and the size of the corrugated steel web in practical engineering designing provide a certain references.
\end{abstract}

Keywords: Corrugated Steel Web, Buckling Strength, Elastic Condition, Abaqus

\section{Introduction}

With the increase of span of bridge, box girder is widely used as the superstructure of bridge, which has the characteristics of large bending and torsion rigidity. But there is a problem that the weight of superstructure increasing with the increase of span, so reducing the weight of the bridge superstructure has become an important direction in the technology of bridge structure. There are two aspects to reduce the weight of superstructure that reduce the thickness of the roof and floor. Because the roof and floor need to meet the requirements of bridge bending design, the thickness of the roof and floor of the bridge is less optimized, while the web needs pre embedded prestressing tendon, then it needs to retain a certain thickness. So the French proposed a project that replace traditional concrete webs of prestressed concrete box girder with plane steel plate, and inflict prestressing force on pre-stressed beam through tension external prestressing tendons. [1,2] The kind of steel-concrete composite bridge has some advantages that less weight, improve the efficiency of the using materials through making full use of potential of materials, improve the performance of construction. But because of shrinkage and creep of concrete roof and floor are restricted by steel web beam, prestressing force is transferred toward webs, which reduces utilization ratio of prestressing force.[2] In 1975, Camernon Bernard proposed that replaced plane steel web with corrugated steel web. [3, 4] Because of corrugated steel web can longitudinal free contraction with shrinkage and creep of concrete roof and floor, it avoids the prestressing force loss due to web avoiding prestressing force.

\section{Researching on Buckling Performance}

Because the longitudinal rigidity of corrugated steel web is small, almost all the bending moment is taken up by concrete slab, and the corrugated steel web mainly bears the vertical shear stress. [5, 6] There are mainly three buckling cases of corrugated steel web under the shear loading: local buckling model, global buckling model and composite buckling model [7], this paper mainly studies the buckling performance of corrugated steel web under the elastic conditions.

1). Elastic Local Buckling Strength

Local buckling means that the buckling occurs only on a sub plate, as shown in Figure 1(a). At this point, the buckling strength can be reduced to a series of boards. The vertical edges are supported by each other, and the horizontal edges are supported by concrete slabs, which are subjected to shear action, and the elastic buckling stress can be obtained:

$$
\tau_{c r l, e}=k_{s} \frac{E \pi^{2}}{12\left(1-v^{2}\right)}\left(\frac{t_{w}}{\omega}\right)^{2}
$$

$E, \quad v-$ Modulus of elasticity and Poisson ratio of 
Corrugated Steel Web;

$t_{w}-$ Thickness of Corrugated Steel Web;

$\omega$-Board width, choses wider board between plane board and inclined board;

$k_{s}-$ Buckling coefficient, means function of length-width ratio $\frac{\omega}{h_{w}}$ ( $h_{w}$ means web height) and boundary condition, calculated according to the following method.

(1) When the long-side simply supported and short-side fixed:

$$
k_{s}=5.34+2.31 \frac{\omega}{h_{w}}-3.44\left(\frac{\omega}{h_{w}}\right)^{2}+8.39\left(\frac{\omega}{h_{w}}\right)^{3}
$$

(2) When the board fixed:

$$
k_{s}=8.98+5.6\left(\frac{\omega}{h_{w}}\right)^{2}
$$

(3) When the board simply supported:

$$
k_{s}=5.34+4.0\left(\frac{\omega}{h_{w}}\right)^{2}
$$

2). Elastic Global Buckling Strength

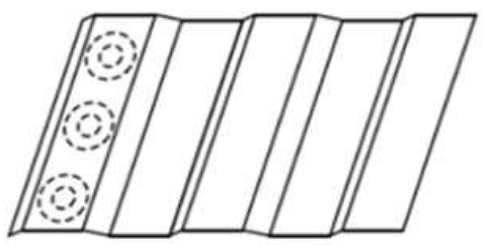

(a) The Local Buckling Model

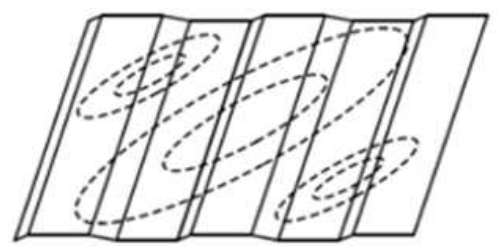

(b) The Global Buckling Model

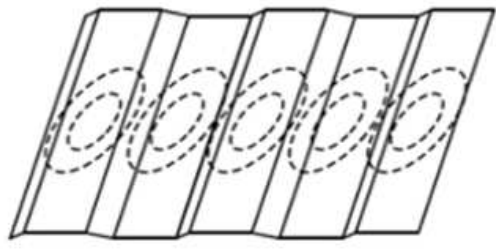

(c) The Composite Buckling Model

Figure 1. Shear buckling mode of corrugated steel web.

Global buckling means that the degree of buckling cover multiple boards or even the whole web, as shown in Figure 1(b). Easley compared Easley-McFarland Formula, Bergmann-Reissner Formula and Hlavacek Formula [8], and given a result that was theoretically reasonable and consistent with the actual results:

$$
\tau_{c r g, e}=k_{g} \frac{D_{x}^{\frac{1}{4}} D_{y}^{\frac{3}{4}}}{t_{w} h_{w}^{2}}
$$

$k_{g}-$ Global buckling coefficient, depends on the boundary condition of the corrugated steel web, take 36 in the text;

$D_{x}, D_{y}-$ The flexural rigidity of the lower plate under the condition of weak and strong flexural rigidity.

$$
\begin{gathered}
D_{x}=\frac{q_{w}}{s_{w}} \frac{E t_{w}^{3}}{12} \\
D_{y}=\frac{E I_{y}}{q_{w}} \\
I_{y}=2 b_{w} t_{w}\left(\frac{h_{w r}}{2}\right)^{2}+\frac{t_{w} h_{w}^{3}}{6 \sin \theta_{w}}
\end{gathered}
$$

$q_{w}$ Length of a single waveform

$$
q_{w}=2\left(b_{w}+d_{w}\right)
$$

$s_{w} \quad$ Contour length of a single waveform

$$
s_{w}=2\left(b_{w}+\frac{d_{w}}{\cos \theta_{w}}\right)
$$

Specific symbols of corrugated steel web structures in the above formula are shown Figure 2.

3). Elastic Composite Buckling Model

Composite buckling model means that although there are several boards involved in buckling, buckling occurs only at a certain height of the web, as shown in Figure 1(c).

\section{Finite Element Analysis}

In this paper, the finite element software Abaqus is used to simulate the corrugated steel web. The main research model in the elastic range of corrugated steel web buckling mode and the force situation, which the model is only in the ideal model of linear elastic, without considering the structure of the initial stress state and geometric nonlinear and material nonlinear factors.

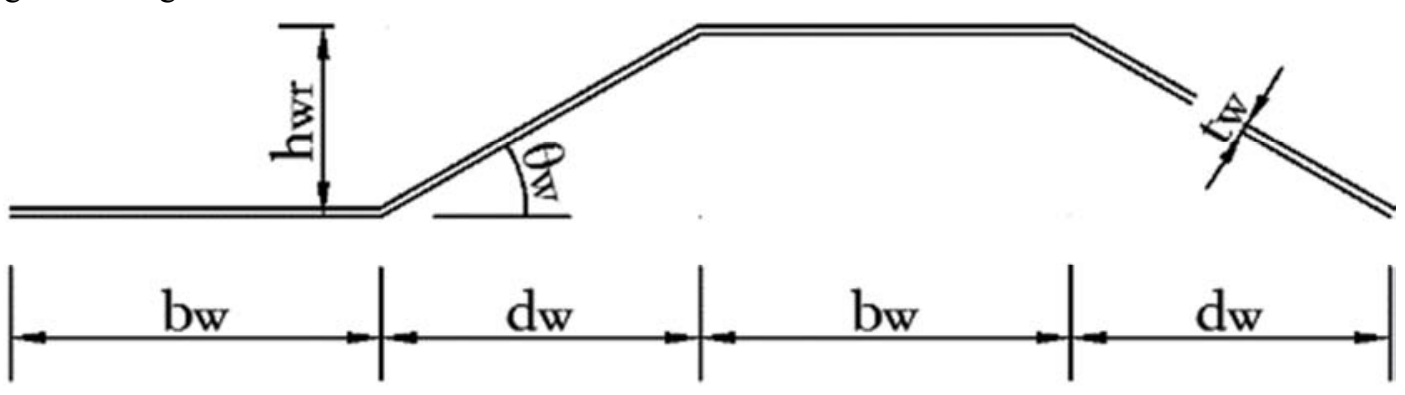

Figure 2. Symbol of size on corrugated structure. 
In this paper, the finite element software Abaqus is used to simulate the corrugated steel web. The main research model in the elastic range of corrugated steel web buckling mode and the force situation, which the model is only in the ideal model of linear elastic, without considering the structure of the initial stress state and geometric nonlinear and material nonlinear factors.
In this model, the actual composite bridge with corrugated steel webs is simplified. Only considers the corrugated steel web. The constraint condition of edges are showed in Table 1. The model is a shell element and the mechanical parameter of the model is the elastic modulus $E=206000 \mathrm{MPa}$, Poisson ratio $v=0.3$ and density $\rho=7.8 \times 10^{-9} t / \mathrm{mm}^{3}$.

Table 1. Constraint condition.

\begin{tabular}{lllll}
\hline & Upper Edge & Lower Edge & Left Edge & Right Edge \\
\hline U1 & $\sqrt{ }$ & $\sqrt{ }$ & & $\sqrt{ }$ \\
U2 & & $\sqrt{ }$ & $\sqrt{ }$ & $\sqrt{ }$ \\
U3 & $\sqrt{ }$ & $\sqrt{ }$ & & \\
UR1 & $\sqrt{ }$ & $\sqrt{ }$ & \\
UR2 & $\sqrt{ }$ & & \\
UR3 & & & \\
\hline
\end{tabular}

\subsection{Influence of Web Thickness on Buckling}

The thickness of corrugated steel web used in actual engineering is $8 \sim 28 \mathrm{~mm}$. [9] The model keep straight length $b_{w}=430 \mathrm{~mm}$, wave angle $\theta_{w}=30.8^{\circ}$, horizontal length of inclined plate $d_{w}=370 \mathrm{~mm}$, wave height $h_{w r}=220 \mathrm{~mm}$, web height $h_{w}=3000 \mathrm{~mm}$ unchanging. Only change the thickness of corrugated steel webs, and the range of change is $8 \sim 20 \mathrm{~mm}$, tolerance is $\delta=2 \mathrm{~mm}$.

Compared the solution that obtained by Abaqus with formula (1) and formula (5). The influence of the thickness of the corrugated steel webs on the buckling is obtained by analyzing the data. The results are shown in Table 2 and Figure 3.

Table 2. Buckling stress of corrugated steel web with different web thicknesses.

\begin{tabular}{lllll}
\hline \multirow{2}{*}{ No. } & $\boldsymbol{t}_{\boldsymbol{w}}(\mathbf{m m})$ & Abaqus $(\mathbf{M P a})$ & Formula \\
\cline { 4 - 5 } & & & The Local (MPa) \\
2 & 8 & 278.4 & 349.1 & \\
3 & 10 & 423.2 & 545.4 & 1105.5 \\
4 & 12 & 581.6 & 785.4 & 1235.9 \\
5 & 14 & 725.5 & 1069.0 & 1353.9 \\
6 & 16 & 1022 & 1396.3 & 1462.4 \\
7 & 18 & 1249 & 1767.2 & 1653.4 \\
\hline
\end{tabular}

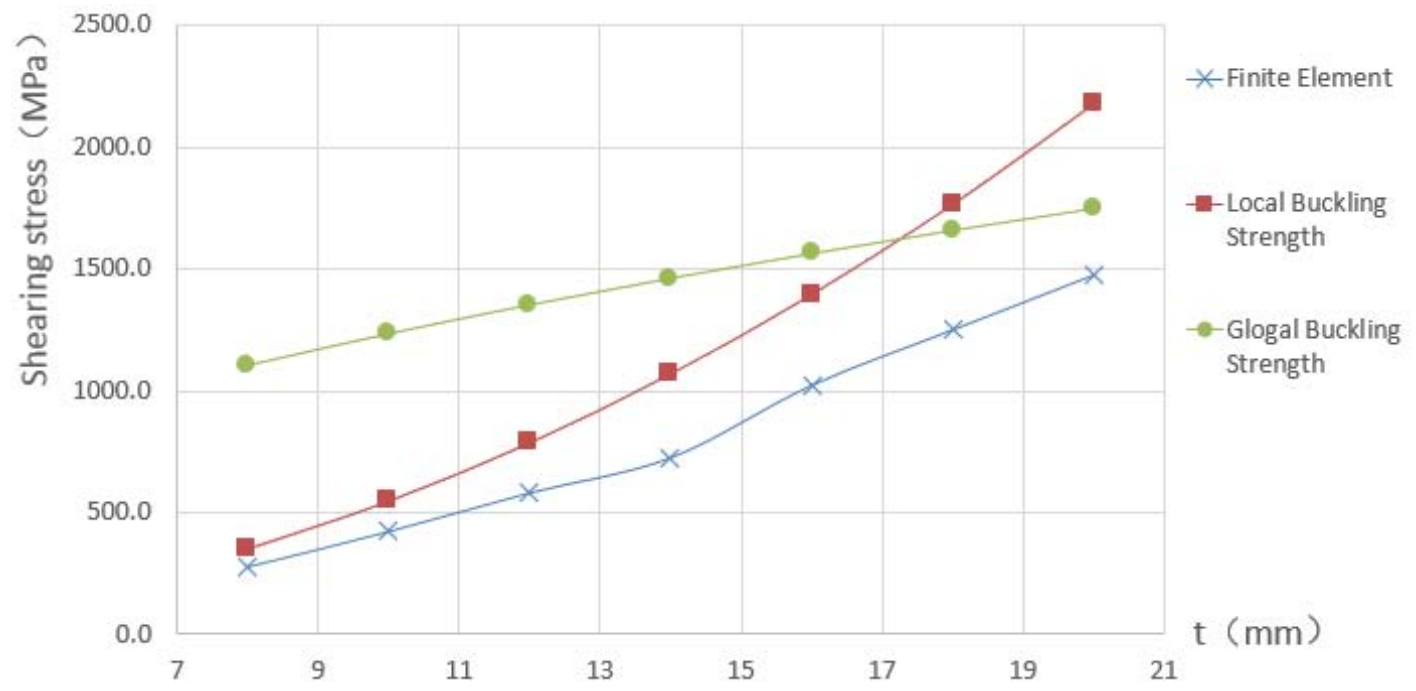

Figure 3. Changing curve about buckling shearing stress with different web thicknesses.

It can be seen from Table 2 and Figure 3 that the theoretical calculation results are much larger than the shear yield strength of materials. The model in the thickness is $8 \sim 16 \mathrm{~mm}$, the local buckling strength is less than the global buckling strength, the structure shows the local buckling mode, when the thickness is too large, the global buckling strength is less than the local buckling strength, the structure is in the global buckling mode, thus it can be seen that when the thickness of 
corrugated steel web design reasonable, structure buckling high enough to ensure the strength of corrugated steel webs in materials before the failure of instability. According to the calculation results of Abaqus, the buckling of corrugated steel webs is the trend of buckling mode from local buckling to global buckling with the increase of thickness, and the results is consistent with the theoretical results.

\subsection{Influence of Wave Angle on Buckling}

The model fixes wave height and changes angle. Keep straight length $b_{w}=430 \mathrm{~mm}$, thicknesses $t_{w}=10 \mathrm{~mm}$, wave height $\mathrm{h}_{\mathrm{wr}}=220 \mathrm{~mm}$, web height $\mathrm{h}_{\mathrm{w}}=3000 \mathrm{~mm}$ unchanging, the wave angle is taken respectively $\theta_{\mathrm{w}}=20^{\circ} 22.9^{\circ} 25.1^{\circ} 26.8^{\circ}$ $30.8^{\circ} 32.9^{\circ} 35.4^{\circ} 37.2^{\circ} 40.3^{\circ}$. The comparison results are shown in Table 3 and Figure 4.

Table 3. Buckling stress of corrugated steel web with different angle.

\begin{tabular}{lllll}
\hline \multirow{2}{*}{ No. } & $\boldsymbol{\theta}_{\boldsymbol{w}}$ & Abaqus (MPa) & Formula \\
\cline { 3 - 4 } & & & The Local (MPa) & The Glogal (MPa) \\
2 & 20 & 234.3 & 279.6 & 561.0 \\
3 & 22.9 & 273.9 & 375.6 & 726.6 \\
4 & 25.1 & 353.7 & 457.9 & 857.3 \\
5 & 26.8 & 387.8 & 533.2 & 968.6 \\
6 & 30.8 & 423.2 & 545.4 & 1233.4 \\
7 & 32.9 & 473.2 & 545.4 & 1388.1 \\
8 & 35.4 & 513.3 & 545.4 & 1568.8 \\
9 & 37.2 & 557.8 & 545.4 & 1705.9 \\
\hline
\end{tabular}

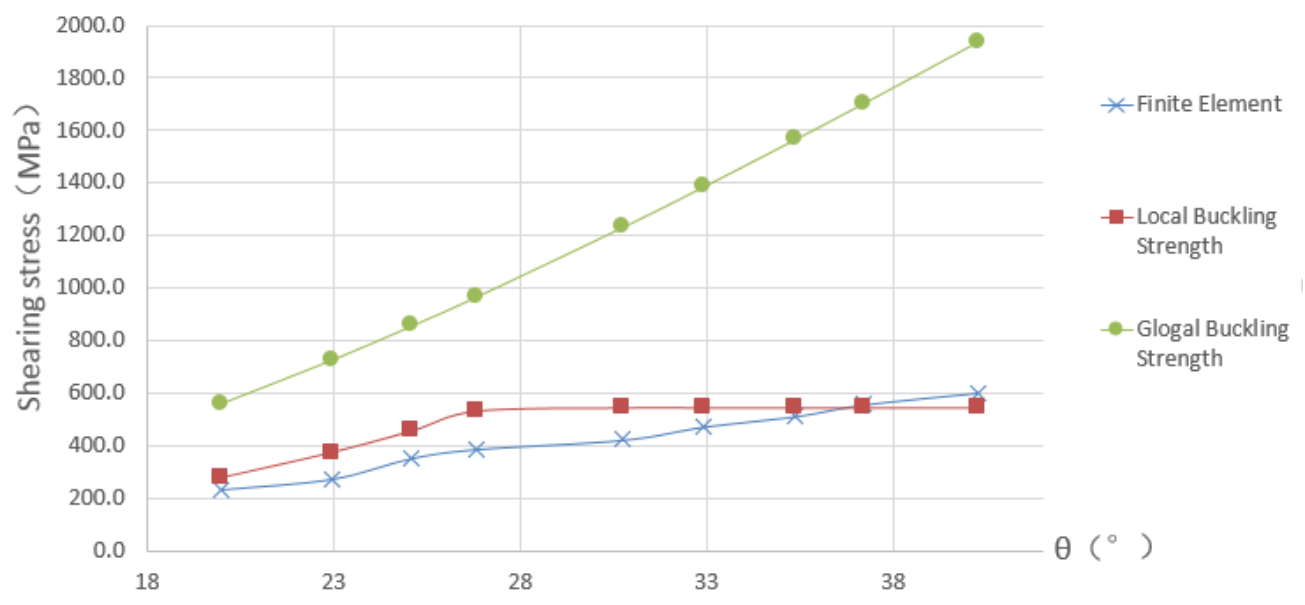

Figure 4. Changing curve about buckling shearing stress with different angle.

It can be seen from Table 3 and Figure 4 that the local buckling strength and the global buckling strength are larger than the shear yield stress, so the buckling instability of the structure is not guaranteed until the yield strength is destroyed. From the theoretical calculation formula in the chart can be seen that with the increase of angle, local buckling strength and global buckling strength are increased, but when the angle is $30.8^{\circ}$. The local buckling strength curve appears a inflection point, after the local buckling strength curve is shown as a horizontal line, that means the local buckling strength is not changed with the angle increasing; but from the global buckling strength curve can be seen that the global buckling strength is linear growth, indicating that increasing the angle will make the buckling strength is obviously improved. But the design angle cannot increase unlimited, it will increase the weight of the web, so instead of structure stress counterproductive. So in the design, need to set angular with balancing the various factors.

\subsection{Influence of Straight Length on Buckling}

The model only changes the straight length, and the range is $b_{w}=230 \mathrm{~mm} \sim 630 \mathrm{~mm}$, tolerance is $\delta=100 \mathrm{~mm}$, keeps thickness $t_{w}=10 \mathrm{~mm}$, wave angle $\theta_{w}=30.8^{\circ}$, wave height $h_{w r}=220 \mathrm{~mm}$, web height $h_{w}=3000 \mathrm{~mm}$ unchanging. The comparison results are shown in Table 4 and Figure 5.

Table 4. Buckling stress of corrugated steel web with different lengths of straight.

\begin{tabular}{|c|c|c|c|c|}
\hline \multirow{2}{*}{ No. } & \multirow{2}{*}{$b_{w}(\mathrm{~mm})$} & \multirow{2}{*}{ Abaqus (MPa) } & \multicolumn{2}{|l|}{ Formula } \\
\hline & & & The Local (MPa) & The Glogal (MPa) \\
\hline 1 & 230 & 599.2 & 733.8 & 373.0 \\
\hline 2 & 330 & 578.2 & 733.8 & 751.2 \\
\hline 3 & 430 & 423.2 & 545.4 & 1235.9 \\
\hline 4 & 530 & 257.2 & 361.9 & 1814.7 \\
\hline 5 & 630 & 187.4 & 258.5 & 2477.8 \\
\hline
\end{tabular}




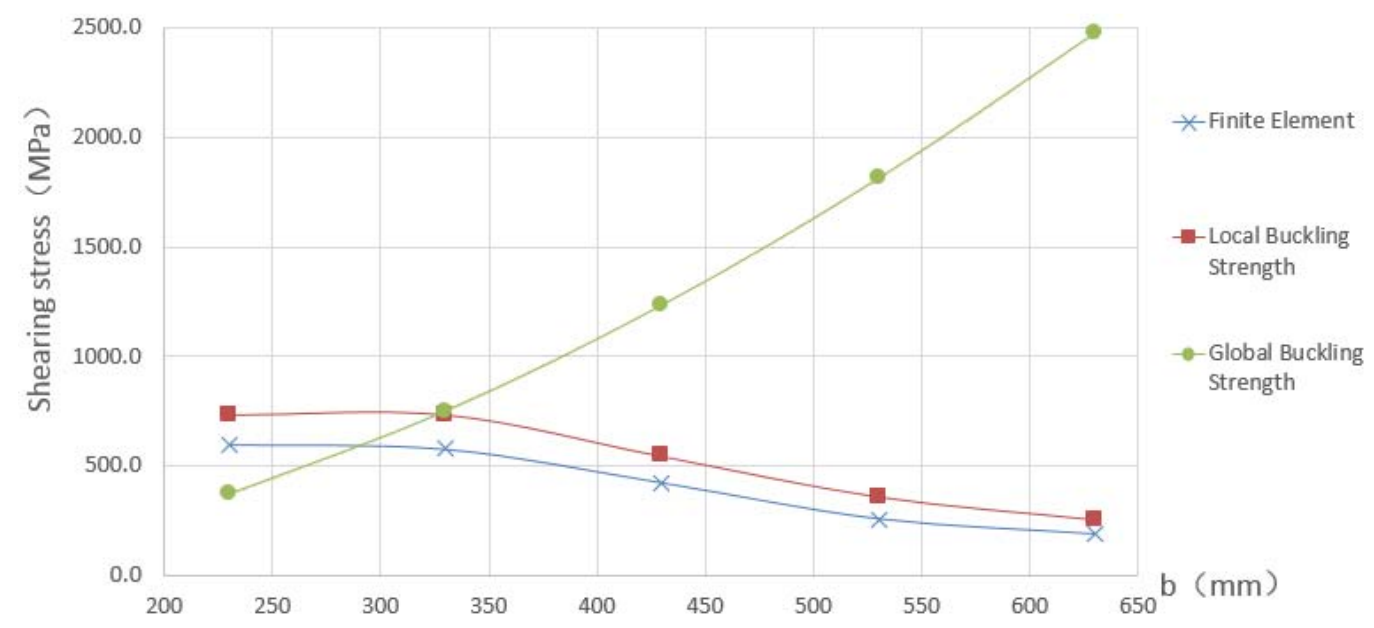

Figure 5. Changing curve about buckling shearing stress with different lengths of straight.

It can be seen from Table 4 and Figure 5 that with the increase of the straight length, global buckling strength increases and local buckling strength decreases gradually. From the beginning of the straight length $b_{w}=230 \mathrm{~mm}$, global buckling strength is less than the local buckling strength, the structure shows the global buckling mode, with the increase of the straight length, the buckling mode will be transformed from local buckling to global buckling. The finite element curve in Figure 5 is similar to the local buckling strength curve, which shows that the results of the finite element simulation are closer to the local buckling strength. Such as the global buckling strength, can be seen from the theoretical formula, the global buckling strength of the structure increases with the increase of the length of the straight, and growing too fast, so when the length of straight is relatively large, the global buckling strength is too conservative. So when design the length of straight, cannot consider the global buckling condition.

\subsection{Influence of Wave Height on Buckling}

The model keeps web height $h_{w}=3000 \mathrm{~mm}$, wave angle $\theta_{w}=30.8^{\circ}$, straight length $b_{w}=230 \mathrm{~mm}$, thickness $t_{w}=10 \mathrm{~mm}$ unchanging, and changes wave height $h_{w r}$, and the range is $140 \mathrm{~mm} \sim 300 \mathrm{~mm}$, tolerance is $\delta=100 \mathrm{~mm}$, The comparison results are shown in Table 5 and Figure 6.

Table 5. Buckling stress of corrugated steel web with different wave heights.

\begin{tabular}{lllll}
\hline No. & $\boldsymbol{h}_{\boldsymbol{w r}}(\mathbf{m m})$ & Abaqus $(\mathbf{M P a})$ & Formula & The Glogal (MPa) \\
\hline 1 & 140 & 514.3 & 545.4 & 583.1 \\
2 & 160 & 499.2 & 545.4 & 685.7 \\
3 & 180 & 468.2 & 545.4 & 789.0 \\
4 & 200 & 457.3 & 545.4 & 892.7 \\
5 & 220 & 423.2 & 545.4 & 996.3 \\
6 & 240 & 403.2 & 545.4 & 1099.8 \\
7 & 260 & 362.3 & 529.7 & 1203.0 \\
8 & 280 & 314.8 & 457.9 & 1305.7 \\
9 & 300 & 289.7 & 399.9 & 1407.9 \\
\hline
\end{tabular}

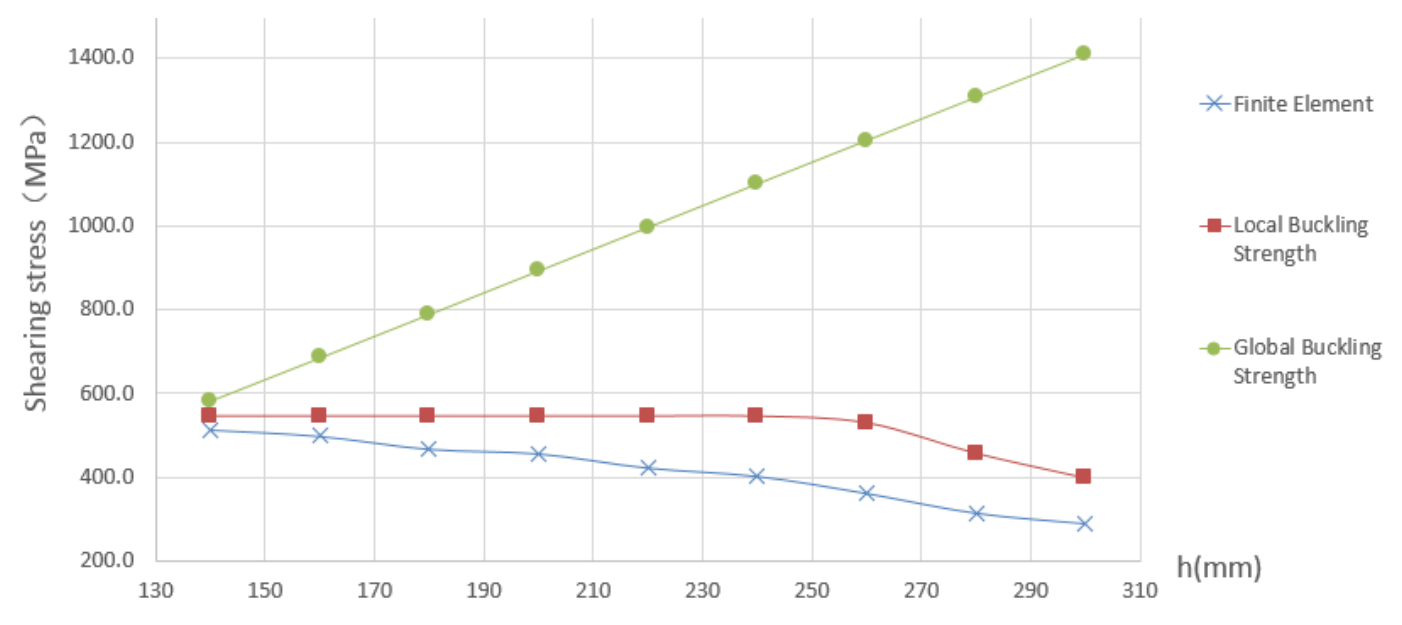

Figure 6. Changing curve about buckling shearing stress with different wave heights. 
It can be seen from Table 5 and Figure 6 that the buckling strength is larger than the yield strength, so that the yield strength failure can be guaranteed before buckling occurs. The wave height is less than $240 \mathrm{~mm}$, the theory of local buckling strength unchanged, the length of inclined plate is smaller than the straight length, that local buckling strength depends on the straight length, when the wave height is larger than $240 \mathrm{~mm}$, the local theory of strength began to decrease. From the local buckling strength formula, can be seen the local buckling strength depends on the size of $\omega$ (broad width, take on the wider between the length of straight and inclined plate length), so when keep the length of straight constant and inclined plate length is less than the length of the plate, the local buckling strength will remain constant; when the inclined plate length is greater than the straight the length of the local buckling strength of the size depends on the length of the inclined plate (here is depends on the wave height), from the local buckling strength curve can be seen, increasing local buckling strength decreases with wave height. The theory whole buckling strength increases with the increase of wave height, so combined with the trend of local buckling and global buckling can know for waveform design, keeps angle unchanging, should ensure that the inclined plate is less than the length of the straight, thereby preventing abdominal plate caused by inclined plate buckling is too long in advance. According to the results of finite element software, it is found that it is consistent with local buckling strength.

\section{Conclusion}

The research shows that the effect of thickness on the buckling strength of corrugated steel webs in performance increases with the thickness of local buckling and global buckling strength are increased, but because the local buckling strength of the growth rate of growth than the global buckling strength speed, so as to increase the thickness of web structure, the global buckling occurs first occurred after the local buckling wave. Angle effect on the buckling strength of the performance with the increase in the thickness of web, local and global buckling strength are increased, but when the angle increases to a certain value, the buckling strength has increased but the increasing amplitude decreases. Influence of straight length on the buckling strength of the performance in the premise when other factors remain unchanged. Straight length is small, buckling of corrugated steel webs with global buckling, with the increase of the length of the straight, global buckling strength increases, but the local buckling strength is reduced. Height of corrugated steel webs on the buckling strength performance in other factors under the condition of constant height affect the inclined plate length, while the horizontal inclined plate is smaller than the length of straight length, local buckling structure, when the horizontal inclined plate length is greater than the straight length [10, 11], local buckling strength decreases with height but the global buckling strength decreases with the increase of wave height increases.

In this paper, the elastic buckling strength of corrugated steel webs is analyzed, but the design of corrugated steel webs has certain guiding function. In the design of the dimension of corrugated steel web, the influence of different size factors on the buckling performance of corrugated steel webs can be referred to the above analysis results. A web dimension with actual force is designed. At the same time, also need to see the defect of linear analysis, so the research on the buckling performance of corrugated steel webs also need to analyze the nonlinear buckling strength analysis, by considering the initial defects and some nonlinear factors, so that it can more close with the actual.

\section{References}

[1] Li Bingnan, Sun Baojun, Li Yanhe. Latest Advances of Externally Prestressed Concrete Bridge Techniques. World Bridge, 2003; 3: 70-73.

[2] Li Hongjiang, Wan Shui, Ye jianshu. Structural Features of Prestressed Concrete Box-girder with Corrugated Steel Webs. Journal of Highway and Transportation Research and Development, 2002; 19(3): 53-57.

[3] Nie Jianguo. Steel-Concrete Composite Bridge. Beijin: China Communications Press, 2011: 305.

[4] Wang Yili. Research on Mechanical Behavior of High-Pier and Long-Span Rigid Frame Continuous Combination Bridge with Corrugated Steel Webs. Jiangsu: SouthEast University, 2014: 3.

[5] Di Jin, Zhou Xuhong, Kong Xiangfu, Chen Delin, Zhang Qian. Experimental Research on Pre-stressed Concrete Composite Box Girders with Corrugated Steel Webs. Journal of Chang'an University (Natural Science Edition), 2009; 29(5): 64-70.

[6] Li Minghong. The Shear Strenth of Girders with Corrugated Steel Webs. Jiangsu: SouthEast University, 2014: 34.

[7] Dai Guangpeng. Large-Span Double-Limb Rigid Frame Bridge with BCSW Study. Jiangxi: East China Jiaotong University, 2012: 38 .

[8] Nie Jianguo, Tang Liang. Global Shear Buckling of Corrugated Steel Plates with Edges Elastically Restrained Against Rotation. Engineering Mechanics, 2008;25(3): 2.

[9] Zhang Qi. Research on Shear Buckling Stability of Prestress Corrugated Steel Webs. Ganshu: Lanzhou Jiaotong University, 2015: 42.

[10] Hu Huawan, Li Jun, Qiang Shizhong. Study on Shear Buckling Property of Corrugated Steel Web PC Combined Box Girder. Journal of Railway Engineering Society, 2011; 2: 82.

[11] Yang Jian. Study on The Stability of PC Composite Box Girder with Corrugated Steel Webs. Ganshu: Lanzhou Jiaotong University, 2014: 33. 